\title{
Multimetric Index to Evaluate Water Quality in Lagoons: A Biological and Geomorphological Approach
}

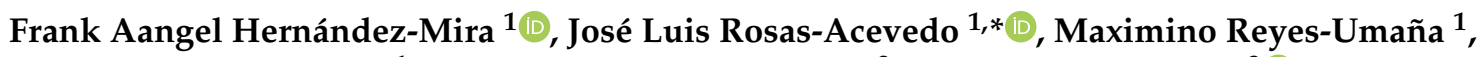 \\ Juan Violante-González ${ }^{1}$, José María Sigarreta-Almira ${ }^{2}$ and Nodari Vakhania ${ }^{3}$ (i) \\ 1 Regional Development Sciences Center, Autonomous University of Guerrero, Los Pinos s/n, Suburb El Roble, \\ Acapulco 39640, Guerrero, Mexico; frankmira@uagro.mx (F.A.H.-M.); 11471@uagro.mx (M.R.-U.); \\ viojuang@yahoo.com.mx (J.V.-G.) \\ 2 Faculty of Mathematics, Autonomous University of Guerrero, Carlos E. Adame 5, Col. La Garita, \\ Acapulco 39640, Guerrero, Mexico; 14366@uagro.mx \\ 3 Science Research Center, Autonomous University of Morelos, Av. Universidad 1001, Chamilpa, \\ Cuernavaca 62206, Morelos, Mexico; nodari@uaem.mx \\ * Correspondence: 05722@uagro.mx
}

check for updates

Citation: Hernández-Mira, F.A.; Rosas-Acevedo, J.L.; Reyes-Umaña, M.; Violante-González, J.; Sigarreta-Almira, J.M.; Vakhania, N. Multimetric Index to Evaluate Water Quality in Lagoons: A Biological and Geomorphological Approach. Sustainability 2021, 13, 4631. https://doi.org/10.3390/ su13094631

Academic Editor: Daeryong Park

Received: 3 March 2021

Accepted: 8 April 2021

Published: 21 April 2021

Publisher's Note: MDPI stays neutral with regard to jurisdictional claims in published maps and institutional affiliations.

Copyright: (c) 2021 by the authors. Licensee MDPI, Basel, Switzerland. This article is an open access article distributed under the terms and conditions of the Creative Commons Attribution (CC BY) license (https:// creativecommons.org/licenses/by/ $4.0 /)$.

\begin{abstract}
In recent years, Multimetric Indices (MMIs) have received a lot of attention thanks to their ability to develop integrative evaluations of water quality, particularly in lagoons. In this article, we propose a new MMI for determining the water quality in lagoons. The proposed index is composed of biotic and abiotic indicators, in particular macroinvertebrates, macrophytes and morphological indicators. The proposed index is based on a geometric representation of a phenomenon associated with an ecological system, the ecosystem elements are mapped as vertices of a network and the relationship between them is represented by the corresponding edges. We classify the status of water bodies, from very low to very high using the ecological quality ratio. We compare our index with different different indices that measure water quality, such as General Biotic Index $(J P(G))$, Macrophyte Index for River (MIR) and Shannon diversity index $\left(\mathrm{H}^{\prime}\right)$ and validate our index with Pearson's correlation coefficient. A strong correlation with the $J P(G)$ and MIR indices $\left(R^{2}=0.8605\right.$ and $R^{2}=0.7661$, respectively) is obtained. Although the proposed index is composed of other indices, the independence of the proposed index with respect to its component indices is proven and the structure of the geometric model associated to the proposed network is studied. A close relationship between the measure called medium articulation and the geometric model associated with the proposed index is highlighted, which allows to determine the missing relationships in the network using structural analysis. The proposed index presents a more comprehensive measure than most indices currently used and has the advantage in the scalability, since other existing indicators can be integrated into our model.
\end{abstract}

Keywords: biomonitoring; geometric model; integrative evaluations; water body

\section{Introduction}

Water bodies are extremely complex and susceptible to human activities; even nature itself is a great stressor of them. Aquatic ecosystem conservation, preservation and management are essential to maintaining the stability of the planet. They are especially important in safeguarding for the continuity of life on Earth. The management of biological and ecological resources requires the ability to perform integrative assessments of aquatic ecosystems (see [1]). Thus, several methods have been developed to assess water quality through biological, geomorphological and physical-chemical indicators that try to interpret the actual situation or the degree of water body alteration.

Biotic indicators as a monitoring approach have been widely applied for health evaluation in aquatic ecosystems. Compared to physical-chemical methods, the advantage of biomonitoring is that it can integrate multiple factors including water quality, habitat 
condition, reservoir development and hydrological modifications on spatial and temporal scales [2-4]. Fish, benthic macroinvertebrates and periphyton are frequently used as good indicators of ecosystem disturbances. Benthic macroinvertebrates are especially good indicators because they live in contact with water bodies and bottom sediments, are relatively immobile compared to fish and are easier to identify than periphyton [5,6]. Since freshwater macroinvertebrate species are sensitive to environmental pollution, it is possible to use their biological structure changes (abundance, variety, dominance and uniformity) to estimate the pollution loads entering the ecosystem (see [7]). Furthermore, macroinvertebrate communities can respond to nutrient enrichment [8], oxygen availability [9], food quantity and quality [10] and changes in habitat structure [11]. Benthic macroinvertebrates are ubiquitous and abundant in most water bodies. Moreover, benthic macroinvertebrates are considered by the Water Framework Directive (WFD) as one of the most important elements in biomonitoring.

Macrophytes belong to the organism groups considered by the WFD for water bodies assessment. Aquatic macrophytes compose an important community in (lenthic) aquatic ecosystems because they are one of the main primary producers, producing high biomass and contributing to biodiversity. Macrophytes in shallow lagoons are involved in various feedback mechanisms that tend to maintain a clear water state, defined by WFD as an expression of quality derived from the structure and functioning of the aquatic system. Evaluation based on macrophytes is associated with the physicochemical characteristics of water quality, mainly nutrients [12] and morphological degradation [13]. Recently, some approaches in monitoring have been critically examined, and the existence of strong correlations between aquatic plants and several water quality determinants has been disputed [14]. Therefore, macrophyte monitoring requires more support utilizing new databases and implementing additional statistical techniques. There are numerous advantages in utilizing macrophytes in monitoring. Similar to macroinvertebrates, macrophytes are visible to the naked eye and therefore convenient for observation. They allow a first approximation to visually assess the ecological status of the water body and make it possible to determine the trophic properties of the water and its acidification [15].

The WFD introduced the term "hydromorphology" as part of its directives, which requires the consideration of any modifications to flow regimen, sediment transport, fluvial morphology and lateral channel mobility. Despite its lesser relative weight in the final qualification of the water body quality, the hydrogeomorphological variable is essential for defining the status of the water body. Recently, increasing effort is being made to develop methods based on sounder geomorphological approaches, with a stronger consideration of physical processes at appropriate spatial and temporal scales [16]. The method proposed in $[17,18]$ and the Morphological Quality Index (MQI) (see [19]) are examples of procedures based on a geomorphological approach.

Given that many economic activities and urban areas are concentrated along the coast, estuaries and other coastal systems such as lagoons are especially affected by anthropogenic pressures resulting in water body degradation. In addition, abiotic processes are intimately linked to biotics, and any alteration of these can alter the health of the resource; thus, the geomorphological and biological conditions are keys in the determination of the health of the water bodies (see [20]). At present, many indices are used to measure water quality in lagoons, e.g., the BMWP and its variants (see [21]), fish-based indices [20], macrophyte indices [15,22] and morphological quality indices (see [17]). These indices are relatively simple to obtain but take only one metric into account in their assessments, resulting in measurements that are not rigorous enough for current needs.

One of the emerging methods to perform the above type of assessments in water bodies are Multimetric Indices (MMIs). MMIs are quantitative global measures that allow to obtain integrate qualitative information about a given system through its most representative elements (see [22]). Since the introduction of MMIs as tools for water quality assessment (cf. [2]), the concept has been applied to more and more biological systems, including wetland plants and terrestrial invertebrates, and they have applied on a range of spatial 
scales from local to continental. In this sense, several MMIs have been developed with the aim of evaluating lagoons health (see $[19,23-25]$ and references therein). These MMIs have in common that they use a single indicator, which reduces the capacity to relate biotic and abiotic elements. Moreover, they become dependent on a single biological community, which can cause greater uncertainty in the assessment.

The data associated with a given ecosystem are dispersed in many ways. MMIs are tools that allow to group all these data and summarizing them as a unique value. For this, it is necessary to collect all the relevant information, i.e., to identify, classify and decide what information in question is more important or relevant. This helps to achieve more efficient and less expensive evaluations for solving the problem while not using redundant information. In this way, biology, together with other scientific disciplines such as mathematics (discrete mathematics), has managed to carry out scientific and technical studies that model ecosystems with greater precision [26].

The aim of this work is to present a MMI proposal for evaluating the water quality of lagoons, based on variation in abundances and pollution tolerance of macroinvertebrates and macrophytes and morphological indicators. We used a discrete approach for this study to describe the relationships between the system elements. We also incorporated concepts of graph theory and its properties.

The rest of the paper is organized as follows. Section 2 defines and conceptualizes the MMI and the geometric model that we use in our study. Section 3 analyzes in detail some characteristics of the proposed MMI. In Section 4, we compare the proposed index with other indices used in the study of water quality and show the independence of the proposed model. The analysis of the structural properties of the geometric model is developed in Section 5. We summarize our results in Section 6 and discuss the future work.

\section{Multimetric Index Conceptualization}

In this section, the MMI fundamentals aspects are formulated and defined. We start with the basic graph terminology and notation.

\subsection{Preliminaries}

We consider $G=(V, E)$ as a finite network, undirected, and without loops or multiple edges, where $V$ represent the vertices set and $E$ the edges set. The order and size of a network, denoted by $n$ and $m$, is the cardinality of its vertex and edge set, respectively.

Given a vertex $v \in V, N(v)$ is the set of neighbors or the open neighbourhood of $v$ in $G$, that is, $N(v)=\{u \in V:(u, v) \in E\}$. For nonempty set $D \subseteq V$, and a vertex $v \in V$, $N_{D}(v)$ denotes the set of neighbors of $v$ in $D$. We denote by $\delta_{G}(v)=|N(v)|$ the degree of vertex $v$ in $G$ (we may omit the argument $G$ when this will cause no confusion). We denote by $\delta=\min _{v \in V}\{\delta(v)\}$ and $\Delta=\max _{v \in V}\{\delta(v)\}$ as the minimum and maximum degree of a network, respectively. Thus, the subnetwork induced by $S \subseteq V$ will be denoted by $G[S]$.

\section{2. $J P(G)$ Index}

JP Index proposed and studied in detail by Pineda et al. $[25,26]$ is based on a bipartite network $G=(V, E)$ where the vertex set $V$ is divided in two disjoint sets $\mathcal{T}$ and $\mathcal{A}$. The vertices in $\mathcal{T}=\left\{t_{1}, t_{2}, \ldots, t_{\max }\right\}$ indicate the tolerance values to pollution. Notice that, for every $t_{i} \in \mathcal{T}$ we have that $\omega\left(t_{i}\right)=i$. Meanwhile, the vertices in $\mathcal{A}=\left\{a_{1}, a_{2}, \ldots, a_{n_{1}}\right\}$ represent the macroinvertebrate grouped in families. The lower values are assigned to insects or aquatic macroinvertebrates with greater pollution tolerance and those with lower tolerance are assigned higher values. Thus, macroinvertebrates with tolerance value of 10 indicate clean waters. In Table 1, a summary of the tolerance value and abundance for the macroinvertebrate families identified between the years 2016 and 2018 in Calderas System from Colombia is shown, as reported in [27]. For every edge $t_{i} a_{j} \in E$ its weight $\omega\left(t_{i} a_{j}\right)$ is the number of individuals in the family $a_{j}$ with tolerance value $t_{i}$. In Figure 1 , a complete bipartite network constructed by JP index methodology is shown, see [26]. 
Table 1. Summary of the tolerance value and abundance for the macroinvertebrate families identified between the years 2016 and 2018 in Calderas System from Colombia (see [27]).

\begin{tabular}{|c|c|c|c|c|c|c|c|}
\hline $\operatorname{Order}\left(\mathcal{A}_{i}\right)$ & Family & Tolerance $\left(\mathcal{T}_{i}\right)$ & Abundance & $\operatorname{Order}\left(\mathcal{A}_{i}\right)$ & Family & Tolerance $\left(\mathcal{T}_{i}\right)$ & Abundance \\
\hline Trombidiformes & Hydrachnidae & 7 & 0 & Hemiptera & Mesoveliidae & 7 & 4 \\
\hline Trombidiformes & Trombidiformes & 6 & 1 & Hemiptera & Miconectidae & 5 & 7 \\
\hline Veneroidea & Sphaeriidae & 3 & 0 & Hemiptera & Naucoridae & 5 & 152 \\
\hline Haplotaxida & Haplotaxida & 5 & 12 & Hemiptera & Notonectidae & 8 & 6 \\
\hline Hygrophila & Physidae & 2 & 103 & Hemiptera & Saldidae & 6 & 1 \\
\hline Hygrophila & Planorbidae & 3 & 0 & Hemiptera & Veliidae & 3 & 754 \\
\hline Neotaenioglossa & Thiaridae & 1 & 9 & Lepidoptera & Crambidae & 8 & 7 \\
\hline Coleoptera & Dryopidae & 5 & 3 & Odonata & Aeshnidae & 8 & 2 \\
\hline Coleoptera & Elmidae & 5 & 2546 & Odonata & Calopterygidae & 7 & 33 \\
\hline Diptera & Blephariceridae & 10 & 10 & Odonata & Coenagrionidae & 5 & 6 \\
\hline Diptera & Ceratopogonidae & 3 & 9 & Odonata & Gomphidae & 8 & 12 \\
\hline Diptera & Chironomidae & 1 & 865 & Odonata & Libellulidae & 6 & 82 \\
\hline Diptera & Dixidae & 4 & 3 & Odonata & Megapodagrionidae & 5 & 1 \\
\hline Diptera & Dolichopodidae & 4 & 1 & Odonata & Platystictidae & 7 & 1 \\
\hline Diptera & Empididae & 5 & 5 & Odonata & Polythoridae & 4 & 0 \\
\hline Diptera & Psychodidae & 3 & 3 & Trichoptera & Calamoceratidae & 7 & 7 \\
\hline Diptera & Simuliidae & 3 & 702 & Trichoptera & Glossosomatidae & 8 & 16 \\
\hline Diptera & Tabanidae & 5 & 0 & Trichoptera & Helicopsychidae & 7 & 82 \\
\hline Diptera & Tipulidae & 3 & 65 & Trichoptera & Hydrobiosidae & 8 & 14 \\
\hline Ephemeroptera & Baetidae & 6 & 1713 & Trichoptera & Hydropsychidae & 4 & 555 \\
\hline Ephemeroptera & Euthyplociidae & 8 & 0 & Trichoptera & Hydroptilidae & 6 & 407 \\
\hline Ephemeroptera & Leptohyphidae & 5 & 866 & Trichoptera & Leptoceridae & 9 & 1053 \\
\hline Ephemeroptera & Leptophlebiidae & 5 & 415 & Trichoptera & Odontoceridae & 10 & 35 \\
\hline Ephemeroptera & Oligoneuriidae & 6 & 2 & Trichoptera & Philopotamidae & 6 & 593 \\
\hline Hemiptera & Belostomatidae & 4 & 9 & Trichoptera & Polycentropodidae & 8 & 19 \\
\hline Hemiptera & Corixidae & 7 & 6 & Trichoptera & Xiphocentronidae & 8 & 1 \\
\hline Hemiptera & Gelastocoridae & 3 & 0 & Decapoda & Pseudothelphusidae & 5 & 0 \\
\hline Hemiptera & Gerridae & 3 & 21 & Tricladida & Dugesiidae & 9 & 2 \\
\hline Hemiptera & Hebridae & 7 & 4 & Basommatophora & Ancylidae & 6 & 0 \\
\hline
\end{tabular}

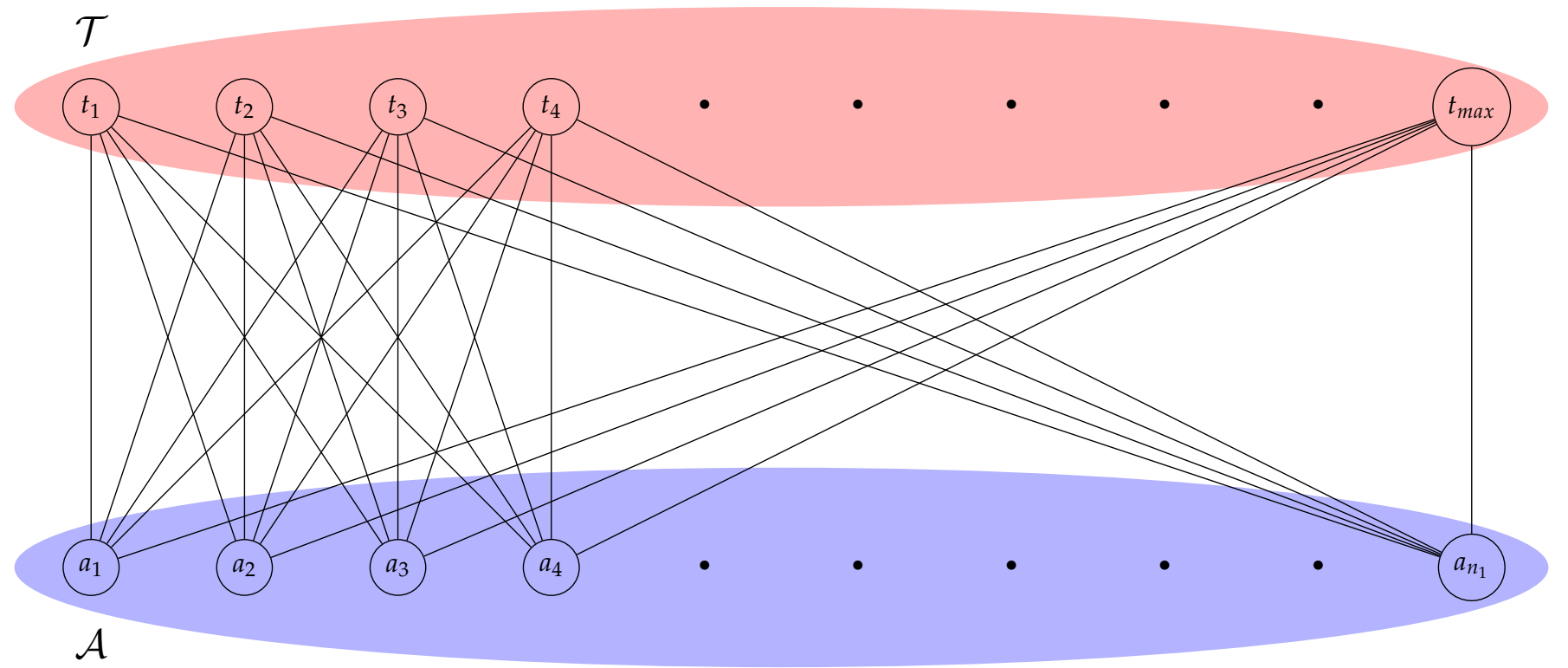

Figure 1. A complete bipartite network constructed by JP index methodology, where $t_{i} \in \mathcal{T}$ and $a_{i} \in \mathcal{A}$.

Finally, in Equation (1) is obtained the value of the JP index [26].

$$
I_{1}(G)=J P(G)=\sum_{t \in \mathcal{T}} \omega(t) \sum_{a \in N_{\mathcal{A}}(t)} \log _{2} \omega(t a)^{1 / \delta(t)}
$$




\subsection{Macrophytes Quality Index $M Q I$}

In this subsection we propose an index, based on the method used in the national Poland monitoring applying the Macrophyte Index for Rivers (MIR) proposed by Szoszkiewicz et al. in [28]. Now we divide the vertex set of the network $G$ in three disjoint set $\mathcal{T}, \mathcal{P}$ and $\mathcal{W}$. The vertices in $\mathcal{T}=\left\{t_{1}, t_{2}, \ldots, t_{\max }\right\}$ represent the same set that in the previous subsection so that macrophytes with tolerance value of $\omega\left(t_{\max }\right)$ indicate clean waters. The vertices in $\mathcal{P}=\left\{p_{1}, p_{2}, \ldots, p_{n_{2}}\right\}$ represent the macrophytes families grouped. Moreover, the vertices in $\mathcal{W}=\left\{w_{1}, w_{2}, \ldots, w_{\max }\right\}$ represents value ranges from 1 plants with a large tolerance range (generalist species) to $\omega\left(w_{\max }\right)$ organisms of a narrow tolerance scope (specialist species). Note that $\omega\left(w_{i}\right)=i$ for every $w_{i} \in \mathcal{W}$.

The relationship between the vertices represents the tolerance value or range value for each macrophytes taxa families (see these relationships in Figure 2). That is, for every edge $t_{i} p_{j} \in E$, where $t_{i} \in \mathcal{T}$ and $p_{j} \in \mathcal{P}$, its weight $\omega\left(t_{i} p_{j}\right)$ is the abundance of individuals in the family $p_{j}$ with tolerance value $t_{i}$. For every edge $w_{i} p_{j} \in E$, where $w_{i} \in \mathcal{W}$, the weight $\omega\left(w_{i} p_{j}\right)$ is the abundance of individuals in the family $p_{j}$ with range value $w_{i}$. Species cover abundance is assessed with a 10-point scale (Table 2).

Table 2. The sampling surface scale coverage by species used to calculate various metrics [29].

\begin{tabular}{cc}
\hline Surface Coverage $(\%)$ & Abundance Value \\
\hline$<0.1$ & 1 \\
$0.1-1$ & 2 \\
$1-2.5$ & 3 \\
$2.5-5$ & 4 \\
$5-10$ & 5 \\
$10-25$ & 6 \\
$25-50$ & 7 \\
$50-70$ & 8 \\
$70-90$ & 9 \\
$\geq 90$ & 20 \\
\hline
\end{tabular}

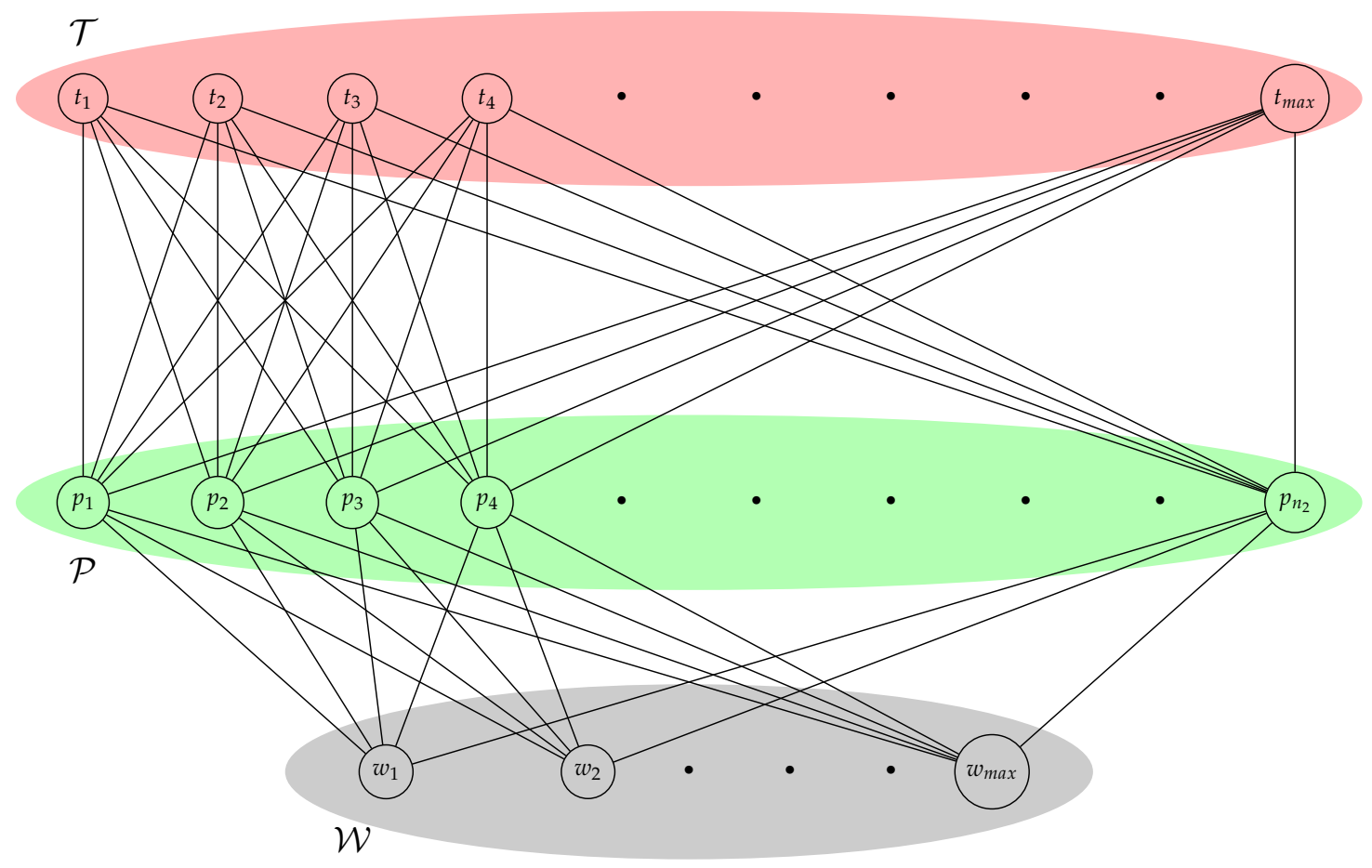

Figure 2. A network constructed by MQI methodology, where $t_{i} \in \mathcal{T}, p_{i} \in \mathcal{P}$ and $w_{i} \in \mathcal{W}$.

Finally, in Equation (2) is obtained the value of the macrophytes quality index. 


$$
I_{2}(G)=\operatorname{MQI}(G)=\frac{\sum_{i=1}^{n_{2}}\left(\sum_{j=1}^{|\mathcal{T}|} \omega\left(t_{j}\right) \omega\left(t_{j} p_{i}\right)+\sum_{k=1}^{|\mathcal{W}|} \omega\left(w_{k}\right) \omega\left(w_{k} p_{i}\right)\right)}{\sum_{i=1}^{n_{2}} \sum_{k=1}^{|\mathcal{W}|} \omega\left(w_{k} p_{i}\right)}
$$

\subsection{Morphological Quality Index MoQI}

This subsection presents a morphological quality index that combines morphological indicators with the earlier mentioned biotic indicators (i.e., the macroinvertebrates and macrophytes). The morphological indicators used to elaborate the index, proposed by Rinaldi et al. [19], are grouped in three sets taking into account their main aspects (continuity, morphology and vegetation) and the components of functionality, artificiality and channel adjustments are evaluated.

Now the set of vertices of the network $G$ represent the morphological indicators, denoted by $\mathcal{M}=\left\{m_{1}, m_{2}, \ldots, m_{n_{3}}\right\}$. The weight of the vertex $m_{i}, 1 \leq \omega\left(m_{i}\right) \leq 10$ takes into account the level of stress presented in the water body: the vertices with weight 1 indicate less stress, and the vertices with weight 10 indicate high levels of stress in in the aquatic ecosystem. Since both macroinvertebrates and aquatic macrophytes are species with little or null movement, it is natural to think that there is an inverse relationship between species abundance and the level of stress in the water body. Since the weights of the vertices of $\mathcal{M}$ are in the range from one to ten, we have a new index based on average abundances and using the inverse relationship between morphological and biotic indicators. A representation of the induced subnetwork by the vertex set $\mathcal{A} \cup \mathcal{P} \cup \mathcal{M}$ is shown in Figure 3.

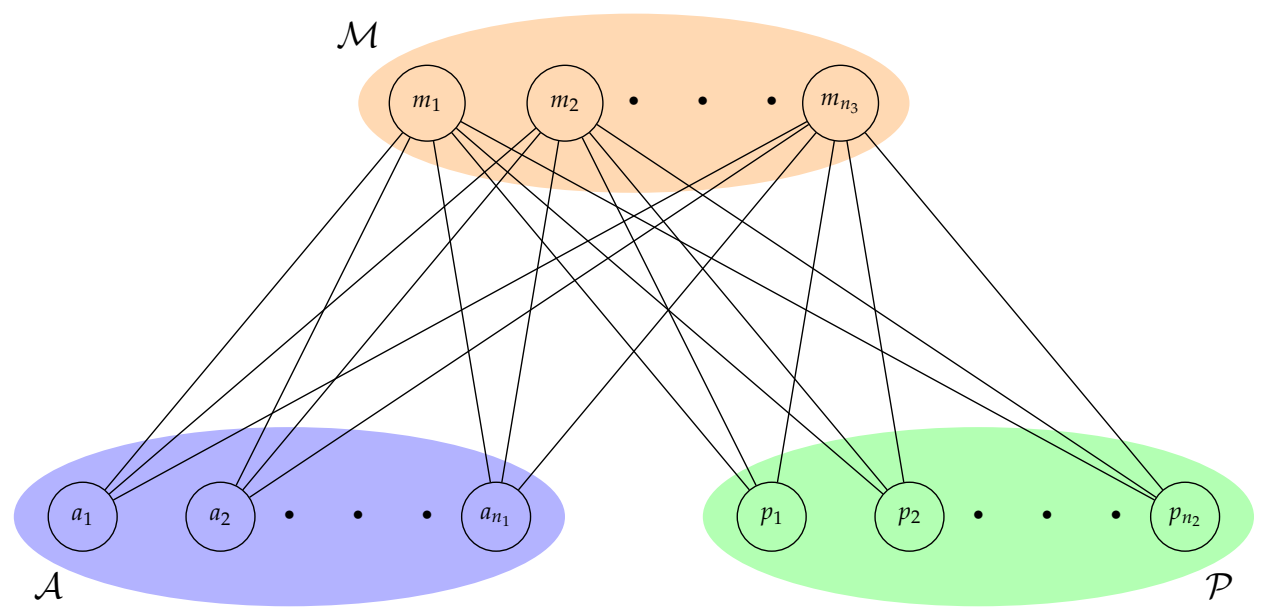

Figure 3. Induced subnetwork by the vertex set $\mathcal{A} \cup \mathcal{P} \cup \mathcal{M}$.

Equation (3) calculates the index relating morphological and biotic indicators.

$$
I_{3}(G)=\sum_{i=1}^{n_{3}} \frac{1}{\omega\left(m_{i}\right)}\left[\sum_{a \in N_{\mathcal{A}}\left(m_{i}\right)} \frac{\log _{2} \omega(a)}{\delta_{\mathcal{A}}\left(m_{i}\right)}+\sum_{p \in N_{\mathcal{P}}\left(m_{i}\right)} \frac{\omega(p)}{\delta_{\mathcal{P}}\left(m_{i}\right)}\right]
$$

Our index can also be represented by the following two equations.

$$
f_{1}(G)=\sum_{i=1}^{n_{3}} \frac{1}{\omega\left(m_{i}\right)} \sum_{a \in N_{\mathcal{A}}\left(m_{i}\right)} \frac{\log _{2} \omega(a)}{\delta_{\mathcal{A}}\left(m_{i}\right)}
$$




$$
f_{2}(G)=\sum_{i=1}^{n_{3}} \frac{1}{\omega\left(m_{i}\right)} \sum_{p \in N_{\mathcal{P}}\left(m_{i}\right)} \frac{\omega(p)}{\delta_{\mathcal{P}}\left(m_{i}\right)}
$$

To take into account the time required for the calculation of the index, the morphological indicators are exposed. These were chosen from the set of indicators proposed in [19], based on their importance for a lagoon ecosystem. Note that the chosen indicators were those relating to morphology and vegetation, because in lagoons the continuity is almost null. We show the chosen indicators in Table 3.

Table 3. Group of morphological indicators proposed in [19], based on their importance for a lagoon ecosystem. The analysis in river channels can be performed in the same way in lagoons, taking into account that the section to be analysed is closed, i.e., the perimeter of the lagoon. The reach length is measured in terms of the perimeters of the lagoon. Likewise, the functional vegetation extension, both longitudinally and areal, is analyzed in the lagoon perimeters.

\begin{tabular}{|c|c|}
\hline Indicator & Description \\
\hline F6 & $\begin{array}{l}\text { Identification of bed configuration in case of presence of transversal structures } \\
\text { and comparison with expected. }\end{array}$ \\
\hline F7 & $\begin{array}{l}\text { Percentage of the reach length with alteration of the natural heterogeneity of } \\
\text { forms expected caused by human factors. }\end{array}$ \\
\hline F8 & Presence/absence of fluvial forms in the alluvial plain. \\
\hline F9 & $\begin{array}{l}\text { Percentage of the reach length with alteration of the natural heterogeneity of } \\
\text { cross section expected type caused by human factors. }\end{array}$ \\
\hline F10 & Presence/absence of alterations of bed sediment. \\
\hline F11 & Presence/absence of large wood. \\
\hline F12 & $\begin{array}{l}\text { Mean width (or areal extension) of functional vegetation in the fluvial corridor } \\
\text { potentially connected to channel processes. }\end{array}$ \\
\hline F13 & $\begin{array}{l}\text { Longitudinal length of functional vegetation along the banks with direct } \\
\text { connection to the channel. }\end{array}$ \\
\hline A8 & $\begin{array}{l}\text { Percentage of the reach length with documented artificial modifications of the } \\
\text { lagoon. }\end{array}$ \\
\hline A9 & $\begin{array}{l}\text { Presence, spatial density and typology of other bed-stabilizing structures (sills, } \\
\text { ramps) and revetments. }\end{array}$ \\
\hline A10 & Existence and relative intensity of past sediment mining activity. \\
\hline A11 & $\begin{array}{l}\text { Existence and relative intensity (partial or total) of streams with natural absence } \\
\text { of riparian vegetation. }\end{array}$ \\
\hline A12 & $\begin{array}{l}\text { Existence and relative intensity (selective or total) of riparian vegetation cuts } \\
\text { during the last } 20 \text { years. }\end{array}$ \\
\hline CA1 & Adjustments in channel pattern. \\
\hline CA2 & Adjustments in channel width. \\
\hline CA3 & Bed-level adjustments. \\
\hline
\end{tabular}

In Figure 4, we illustrate the final discrete structure proposed until this moment. We must take into account each of the above indices to determine the final index, denoted by $I_{f}(G)$ (with which we will evaluate the health of the lagoon ecosystem). To develop the final index we use the idea of the weighted average, where the greater weight indicates have greater importance for the ecosystem. This $I_{f}(G)$ index, includes variables and relations which are not present in other indices reported in the literature (for example, dominant taxon, macroinvertebrate family richness, abundance and richness of macrophytes and the 
relation between biotic elements and morphological indicators). The multimetric index for lagoon ecosistem quality assessment is defined as

$$
I_{f}(G)=\frac{\varphi_{1} I_{1}(G)+\varphi_{2} I_{2}(G)+\varphi_{3} I_{3}(G)}{\varphi_{1}+\varphi_{2}+\varphi_{3}} .
$$

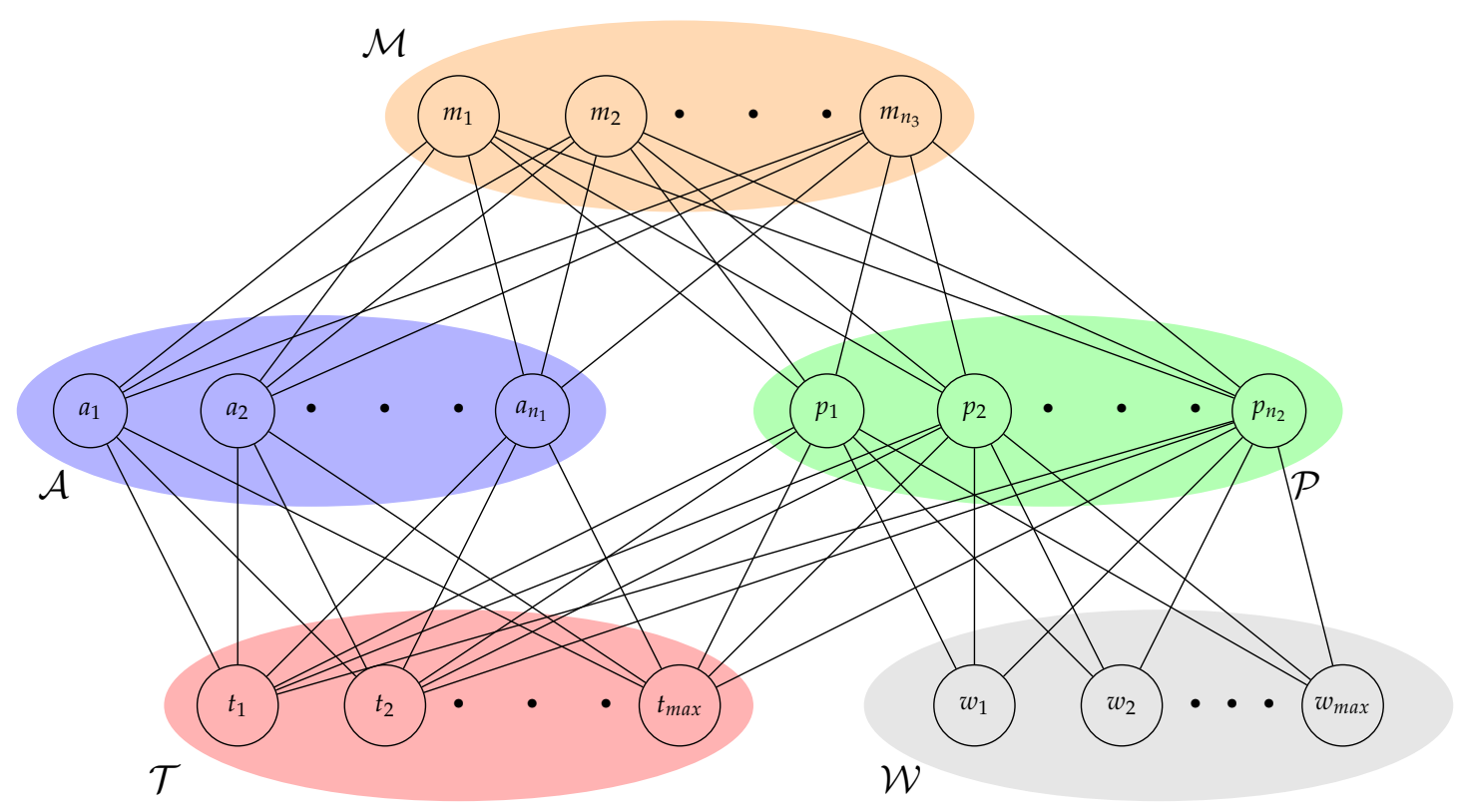

Figure 4. The figure shows a network $G$ representing the discrete model associated with the index $I_{f}(G)$.

\section{Analyzing the MMI}

In this section, we analyze in detail some characteristics of the proposed multimetric index determining lower and higher ranges that the proposed index can reach. Moreover, we establish conditions to efficiently choose the values of the weights of each index.

The maximum and minimum weights among all taxa in the network $G, \Psi$ and $\psi$, respectively, are defined as $\Psi=\max \{\omega(a)\}$ and $\psi=\min \{\omega(a)\}$ for all $a \in \mathcal{A}$. Likewise, $\Phi=\max \{\omega(p)\}$ and $\phi=\min \{\omega(p)\}$ for all $p \in \mathcal{P}$.

Proposition 1. Let $m, a, p$ and $w$ be a vertices belonging to $\mathcal{M}, \mathcal{A}, \mathcal{P}$ and $\mathcal{W}$, respectively. Then, the following conditions hold.

- $1 \leq \omega(m) \leq 10$.

- $1 \leq \omega(w) \leq \omega\left(w_{\max }\right)$

- $\omega(a)=\sum_{i=1}^{|\mathcal{T}|} \omega\left(t_{i} a\right)$

- $\quad \omega(p)=\sum_{i=1}^{|\mathcal{T}|} \omega\left(t_{i} p\right)$.

- $\psi \leq \omega(a) \leq \Psi$.

- $\phi \leq \omega(p) \leq \Phi$.

The following inequality from [25] with lower and upper bound on index $I_{1}(G)$, will be used later for the analysis of our final index:

$$
T * \log _{2}(\psi) \leq I_{1}(G) \leq T * \log _{2}(\Psi),
$$


where $T=\frac{M *(M+1)}{2}$ and $M=\max \{\omega(t)\}$ for all $t \in \mathcal{T}$.

Next, we analyze the maximum and minimum bounds on the macrophyte index $I_{2}(G)$. As mentioned in the previous section, this index is based on the MIR (see Equation (7) and [28]).

$$
M I R=\frac{\sum_{i=1}^{N} L_{i} * W_{i} * P_{i}}{\sum_{i=1}^{N} W_{i} * P_{i}} * 10
$$

We can see that the numerators do match but the denominators do not much. It is easy to see that for the index $I_{2}(G)$ the numerator is greater than or equal to the denominator and that the denominator of our index is the sum of the abundances of each of the species. With this in mind, we propose the following bounds.

Proposition 2. Let $G$ be a network that represent the MMI. Then,

$$
1 \leq I_{2}(G) \leq 10 * \omega\left(w_{\max }\right) .
$$

Proof. As mentioned above, its easy to see that the numerator is greater than or equal to the denominator. Thus, $I_{2}(G) \geq 1$. On the other hand, in our discrete model we can achieve the sum of the abundances as $\sum_{i=1}^{n_{2}} \sum_{k=1}^{|\mathcal{W}|} \omega\left(w_{k} p_{i}\right)$. As the numerators coincide for both the MIR and our index,

$$
I_{2}(G)=\frac{\sum_{i=1}^{N} L_{i} * W_{i} * P_{i}}{\sum_{i=1}^{n_{2}} \sum_{k=1}^{|\mathcal{W}|} \omega\left(w_{k} p_{i}\right)} \leq \frac{10 * \omega\left(w_{\max }\right) * \sum_{i=1}^{n_{2}} \sum_{k=1}^{|\mathcal{W}|} \omega\left(w_{k} p_{i}\right)}{\sum_{i=1}^{n_{2}} \sum_{k=1}^{|\mathcal{W}|} \omega\left(w_{k} p_{i}\right)}=10 * \omega\left(w_{\max }\right) .
$$

The proof is complete.

We note that we will scale index $I_{2}(G)$ (by multiplying it by 10) to normalise the results. In the next propositions lower and upper bounds for the indices $f_{1}(G)$ and $f_{2}(G)$ are obtained.

Proposition 3. Let $G$ be a network that represent the MMI. Then,

$$
\log _{2} \omega(\psi) * \sum_{i=1}^{n_{3}} \frac{1}{\omega\left(m_{i}\right)} \leq f_{1}(G) \leq \log _{2} \omega(\Psi) * \sum_{i=1}^{n_{3}} \frac{1}{\omega\left(m_{i}\right)}
$$

Proof. Notice that $\left|N_{\mathcal{A}}\right|=n_{1}$ for every $m \in \mathcal{M}$. Then by Proposition $1, \psi \leq \omega(a) \leq \Psi$ for all $a \in \mathcal{A}$. Hence,

$$
\begin{aligned}
f_{1}(G) & =\sum_{i=1}^{n_{3}} \frac{1}{\omega\left(m_{i}\right)} \sum_{a \in N_{\mathcal{A}}\left(m_{i}\right)} \frac{\log _{2} \omega(a)}{\delta_{\mathcal{A}}\left(m_{i}\right)}=\sum_{i=1}^{n_{3}} \frac{1}{\omega\left(m_{i}\right)} \sum_{j=1}^{n_{1}} \frac{\log _{2} \omega\left(a_{j}\right)}{n_{1}} \\
& \leq \sum_{i=1}^{n_{3}} \frac{1}{\omega\left(m_{i}\right)} \sum_{j=1}^{n_{1}} \frac{\log _{2} \omega(\Psi)}{n_{1}}=\log _{2} \omega(\Psi) * \sum_{i=1}^{n_{3}} \frac{1}{\omega\left(m_{i}\right)} .
\end{aligned}
$$

Similarly, it can be shown that $f_{1}(G) \geq \log _{2} \omega(\psi) * \sum_{i=1}^{n_{3}} \frac{1}{\omega\left(m_{i}\right)}$ and the proposition is proved. 
Proposition 4. Let $G$ be a network that represent the MMI. Then

$$
\phi * \sum_{i=1}^{n_{3}} \frac{1}{\omega\left(m_{i}\right)} \leq f_{2}(G) \leq \Phi * \sum_{i=1}^{n_{3}} \frac{1}{\omega\left(m_{i}\right)} .
$$

Proof. Note that $\left|N_{\mathcal{P}}\right|=n_{2}$ for every $m \in \mathcal{M}$. By Proposition $1, \phi \leq \omega(p) \leq \Phi$ for all $p \in \mathcal{P}$. Hence,

$$
\begin{aligned}
f_{2}(G) & =\sum_{i=1}^{n_{3}} \frac{1}{\omega\left(m_{i}\right)} \sum_{p \in N_{\mathcal{P}}\left(m_{i}\right)} \frac{\omega(p)}{\delta_{\mathcal{P}}\left(m_{i}\right)}=\sum_{i=1}^{n_{3}} \frac{1}{\omega\left(m_{i}\right)} \sum_{j=1}^{n_{2}} \frac{\omega\left(p_{j}\right)}{n_{2}} \\
& \leq \sum_{i=1}^{n_{3}} \frac{1}{\omega\left(m_{i}\right)} \sum_{j=1}^{n_{2}} \frac{\Phi}{n_{2}}=\Phi * \sum_{i=1}^{n_{3}} \frac{1}{\omega\left(m_{i}\right)} .
\end{aligned}
$$

Similarly, it can be shown that $f_{2}(G) \geq \phi * \sum_{i=1}^{n_{3}} \frac{1}{\omega\left(m_{i}\right)}$ and the proposition is proved.

Corollary 1. Let $G$ be a network that represents the MMI. Then

$$
\sum_{i=1}^{n_{3}} \frac{1}{\omega\left(m_{i}\right)}\left[\log _{2} \omega(\psi)+\phi\right] \leq I_{3}(G) \leq \sum_{i=1}^{n_{3}} \frac{1}{\omega\left(m_{i}\right)}\left[\log _{2} \omega(\Psi)+\Phi\right]
$$

As earlier mentioned, our index assigns the weights to the index of the most important indicators to determine the water quality in a lagoon. In particular, we let $\varphi_{1}=\varphi_{2}=$ $\varphi_{3}=1$ and give equal weights to each of the indices. Then the final index is $I_{f}(G)=$ $\frac{I_{1}(G)+I_{2}(G)+I_{3}(G)}{3}$.

Now we analyze our multimetric index based on the arguments from the above propositions and the established weights. We establish tight bounds for the index.

$$
\begin{gathered}
I_{f}(G) \geq \frac{1}{3}\left(T * \log _{2}(\psi)+\sum_{i=1}^{n_{3}} \frac{1}{\omega\left(m_{i}\right)}\left(\log _{2} \omega(\psi)+\phi\right)+1\right), \\
I_{f}(G) \leq \frac{1}{3}\left(T * \log _{2}(\Psi)+\sum_{i=1}^{n_{3}} \frac{1}{\omega\left(m_{i}\right)}\left(\log _{2} \omega(\Psi)+\Phi\right)+10 * \omega\left(w_{\text {max }}\right)\right) .
\end{gathered}
$$

At this point, we defined the ecological quality ratio $(\mathrm{EQR})$ used to determine the ecological quality status, denoted by $\rho(G)$ dividing the observed value on the expected value of the $I_{f}(G)$ index at a reference location.

$$
\rho(G)=\frac{3 I_{f}(G)}{T * \log _{2}(\Psi)+\sum_{i=1}^{n_{3}} \frac{1}{\omega\left(m_{i}\right)}\left(\log _{2} \omega(\Psi)+\Phi\right)+10 * \omega\left(w_{\text {max }}\right)}
$$

Note that $0 \leq \rho \leq 1$, and it easy to see that if $\rho$ approaches zero, the water quality of the ecosystem is bad, whereas if $\rho$ approaches one, then the water quality of the ecosystem is better. In this way, parameter $\rho$ allows the evaluation of the water quality of the system as a function of several measurable parameters of the system, such as tolerance values, abundance and dominance of the taxas.

In general, the studies that evaluate water quality classify this quality in five classes, commonly, very high, high, regular, low and very low (see $[16,25]$ and its references). To classify the status in our study, the class width is determined by the quotient between the expected value of the $I_{f}(G)$ index at a reference site and the number of classes. The expected 
value of the $I_{f}(G)$ index at a reference site is obtained when the average abundances are uniformly distributed, the stress in the morphological indicators are minimum and there exist all possible relations (edges) in the network $G$ (see Figure 4). Finally, they are used to classify the water quality with our index using the ecological quality ratio proposed in Equation (8). Thus, if $\rho(G) \geq 0.81$ the quality is very high, $0.61 \leq \rho(G) \leq 0.80$ is high, $0.41 \leq \rho(G) \leq 0.60$ is regular, $0.21 \leq \rho(G) \leq 0.40$ is low and if $\rho(G) \leq 0.20$ is very low.

\section{Comparison between Indices to Study Water Quality}

In this section, we compare our index with the several most known indices frequently used in the water quality assessment. We use two of the basis indices of our index and the Shannon diversity index, which is one of the most commonly used ones in this type of study. The basis indices used were $J P(G)$ and MIR index (see $[15,25]$ ).

The Shannon diversity index, denoted by $H^{\prime}$, is commonly used to characterize species diversity in a community. It is applied in natural sciences for the assessment of water quality and frequently accompanies other indices (see more in [30-32]) and is defined as

$$
H^{\prime}=-\sum_{i=1}^{S} p_{i} \ln \left(p_{i}\right)
$$

where $p_{i}$ is the relative abundance of the species, i.e., $p_{i}$ is the quotient between the abundance of the organism and the sum of all the abundances and $S$ is the total number of species in the reference site (macroinvertebrates and macrophytes, recall that the abundances are normalized using $\log _{2} \omega(a)$ and Table 2, respectively).

We simulated 150 randomized networks taking into account the following parameters. To generate the networks, the 17 macroinvertebrate orders proposed in Table 1 were generated with equal probability of presence/absence for each order and maximum abundance of 192 individuals, considering the average abundance for each order of macroinvertebrates reported in [27]. The macrophytes were grouped in eight families (Chlorophyta, Cyanophyta, Rhodophyta, Hepaticophyta, Bryophyta, Pteridophyta, Monocotyledoneae and Dicotyledoneae) with the same probability of presence, ensuring that the sum of the coverages is $100 \%$ and calculating the abundance as shown in Table 2 . The morphological indicators proposed in Table 3 were used with values between 1 and 10 to indicate the level of stress.

On the other hand, in order to see the differences between the indexes and the certainty of $I_{f}(G)$, we simulated the networks whose indices values are shown in Table 4. The first 50 networks (left columns) show networks where dominant individuals and morphological indicators indicate high contamination of the water body, those in the center were simulated such that the contamination of the water was regular, while the networks on the right indicate little or no contamination.

Table 4. It is shown the obtained values of $I_{f}(G), J P(G), M I R, H^{\prime}$ and $\rho(G)$ for 150 randomly constructed networks. The networks were constructed using the macroinvertebrate orders reported in [27], the macrophytes families mentioned above and the morphological indicators previously proposed.

\begin{tabular}{|c|c|c|c|c|c|c|c|c|c|c|c|c|c|c|}
\hline$I_{f}(G)$ & $P(G)$ & $I I R$ & $H^{\prime}$ & $(G)$ & $I_{f}(G)$ & $P(G)$ & 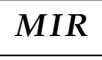 & $H^{\prime}$ & $(G)$ & $I_{f}(G)$ & $P(G)$ & $R$ & $I^{\prime}$ & $(G)$ \\
\hline 14.50 & 19.85 & 52 & 3.45 & 06 & 14585 & & & & & 1181 & & & & .84 \\
\hline S1.0 & & 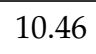 & (1) & & & & & & & & & 77 & דו & 0.83 \\
\hline 57.75 & 95.06 & 10.56 & 3.96 & 0.16 & 146.73 & & 40.09 & T & 0.59 & 211.92 & & 77.02 & 3.97 & 3 \\
\hline 48.23 & 119.33 & 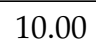 & 3.93 & 0 & 146.40 & 3 & 4 & 4.0 & 0 & 8 & 3 & 0 & 4.01 & 0.84 \\
\hline 53.80 & & 37 & 40 & ר? & & & & 400 & & & & & 40 & 0.84 \\
\hline 58.76 & 149.20 & 10.90 & 4.06 & 0.24 & 146.27 & 320.06 & 41.15 & 4.00 & 0.59 & 215.00 & 370.27 & 79.44 & 4.02 & 0.84 \\
\hline .44 & 15980 & 1.10 & 4.09 & 0.26 & 148.80 & 321.54 & 43.05 & 4.08 & 0.59 & 14.79 & 371. & 79.55 & 4.02 & 0.84 \\
\hline 65.65 & 170.01 & 10.29 & 4.05 & 0.27 & $14 \varepsilon$ & 322.76 & 41.40 & 4.04 & 0.59 & 214.67 & 371 & 77.50 & 4.02 & 0.84 \\
\hline 68.75 & 178.21 & 10.00 & 4.02 & 0.28 & 148.86 & 324.00 & 41.75 & 3.98 & 0.59 & 215.05 & 372.67 & 78.55 & 4.04 & 0.85 \\
\hline
\end{tabular}


Table 4. Cont.

\begin{tabular}{|c|c|c|c|c|c|c|c|c|c|c|c|c|c|c|}
\hline$I_{f}(G)$ & $P(G)$ & $I I R$ & $H^{\prime}$ & $(G)$ & $I_{f}(G)$ & $J P(G)$ & $I I R$ & $H^{\prime}$ & $o(G)$ & $I_{f}(G)$ & $J P(G)$ & $M I R$ & $H^{\prime}$ & $o(G)$ \\
\hline 72.25 & 87.07 & 0.38 & 4.07 & 0.29 & 151.08 & 325.64 & .76 & 4.07 & 0.60 & 211.92 & 373.13 & 6.00 & 3.99 & 0.83 \\
\hline 74.14 & 194.02 & 10.37 & 4.05 & 0.30 & 152.48 & 326.78 & .94 & 4.09 & 0.61 & 214.16 & 3.99 & 7.23 & 3.99 & 0.84 \\
\hline 76.13 & 200.60 & 10.00 & 3.99 & 0.31 & 150.60 & 328.02 & .13 & 4.01 & 0.60 & 215.78 & 374.79 & 8.51 & 4.00 & 0.84 \\
\hline 78.04 & 205.04 & 10.83 & 4.07 & 0.32 & 150.39 & 329.73 & .65 & 3.98 & 0.60 & 220.31 & 375.47 & 79.53 & 4.06 & 0.85 \\
\hline 80.09 & 211.90 & 10.39 & 4.03 & 0.33 & 151.63 & 330.55 & 42.81 & 4.05 & 0.61 & 222.51 & 376.18 & 80.85 & 4.03 & 0.86 \\
\hline 82.29 & 217.80 & 10.42 & 4.06 & 0.33 & 151.24 & 331.77 & 41.72 & 3.99 & 0.60 & 220.06 & 376.90 & 79.86 & 4.04 & 0.85 \\
\hline 83.29 & 221.82 & 10.32 & 4.02 & 0.34 & 152.32 & 333.07 & 40.87 & 3.98 & 0.61 & 219.28 & 377.45 & 77.68 & 4.01 & 0.85 \\
\hline 86.27 & 227.70 & 10.22 & 4.07 & 0.35 & 153.66 & 334.19 & 43.08 & 4.07 & 0.62 & 220.71 & 378.33 & 79.00 & 4.02 & 0.85 \\
\hline 86.25 & 231.04 & 10.00 & 3.99 & 0.35 & 152.08 & 335.40 & 41.01 & 3.97 & 0.61 & 221.20 & 378.92 & 78.59 & 4.02 & 0.85 \\
\hline 88.64 & 235.52 & 10.63 & 4.03 & 0.36 & 154.28 & 336.40 & 42.53 & 4.03 & 0.62 & 222.04 & 379.52 & 79.87 & 4.05 & 0.86 \\
\hline 90.57 & 240.21 & 10.00 & 4.03 & 0.37 & 153.08 & 337.54 & 41.27 & 3.99 & 0.61 & 222.37 & 380.21 & 79.63 & 4.06 & 0.85 \\
\hline 92.21 & 243.20 & 10.41 & 4.05 & 0.37 & 153.01 & 338.75 & 40.44 & 3.97 & 0.61 & 223.24 & 380.93 & 79.86 & 4.05 & 0.85 \\
\hline 93.34 & 246.54 & 10.61 & 4.12 & 0.38 & 155.14 & 339.94 & 42.28 & 4.06 & 0.62 & 220.65 & 381.57 & 78.50 & 3.98 & 0.85 \\
\hline 93.87 & 250.83 & 10.00 & 4.01 & 0.38 & 154.98 & 341.08 & 42.27 & 4.05 & 0.62 & 222.02 & 382.13 & 78.85 & 4.04 & 0.85 \\
\hline 95.41 & 253.87 & 10.16 & 4.05 & 0.39 & 156.63 & 341.88 & 42.85 & 4.05 & 0.63 & 218.33 & 382.74 & 73.90 & 3.94 & 0.84 \\
\hline 96.98 & 256.96 & 10.52 & 4.07 & 0.39 & 158.37 & 343.17 & 43.63 & 4.10 & 0.63 & 222.70 & 383.42 & 78.24 & 4.03 & 0.86 \\
\hline 97.25 & 259.81 & 10.00 & 4.00 & 0.39 & 157.94 & 344.11 & 41.58 & 3.98 & 0.63 & 225.08 & 384.01 & 81.41 & 4.08 & 0.87 \\
\hline 99.07 & 262.82 & 10.64 & 4.10 & 0.40 & 157.13 & 345.06 & 40.56 & 3.97 & 0.63 & 222.84 & 384.75 & 79.12 & 4.03 & 0.86 \\
\hline 99.61 & 266.04 & 10.17 & 4.04 & 0.40 & 158.13 & 346.06 & 42.47 & 4.04 & 0.63 & 223.39 & 385.29 & 79.21 & 4.04 & 0.86 \\
\hline 100.38 & 268.41 & 10.09 & 4.02 & 0.41 & 159.43 & 347.07 & 43.76 & 4.08 & 0.63 & 222.29 & 385.95 & 77.70 & 3.98 & 0.86 \\
\hline 101.29 & 270 & 10.32 & 4.05 & 0.41 & 77 & 18 & 4 & 4 & 4 & 7 & 3 & 7 & 4.00 & 0.85 \\
\hline 102.06 & 273.15 & 10.36 & 4.03 & 0.41 & 157.99 & 349.08 & 40.00 & 3.95 & 0.63 & 221.77 & 387.18 & 77.14 & 3.99 & 0.86 \\
\hline 103.31 & 276.14 & 10.84 & 4.10 & 0.42 & 159.16 & 350.02 & 40.90 & 3.98 & 0.63 & 229.64 & 387.70 & 77.95 & 4.02 & 0.86 \\
\hline 103.99 & 278.80 & 10.00 & 4.03 & 0.42 & 159.18 & 351.18 & 41.67 & 3.97 & 0.63 & 230.50 & 388.27 & 76.56 & 3.99 & 0.86 \\
\hline 104.79 & 281.19 & 10.35 & 4.03 & 0.42 & 161.54 & 352.03 & 42.23 & 4.01 & 0.64 & 228.82 & 388.84 & 78.31 & 4.00 & 0.86 \\
\hline 106.39 & 283.43 & 11.01 & 4.11 & 0.43 & 161.13 & 352.97 & 42.78 & 4.05 & 0.64 & 232.09 & 389.43 & 78.18 & 4.03 & 0.87 \\
\hline 106.44 & 285.48 & 11.18 & 4.04 & 0.43 & 161.62 & 353.76 & 41.89 & 4.04 & 0.64 & 228.29 & 390.07 & 77.71 & 4.01 & 0.86 \\
\hline 106.69 & 287.80 & 10.00 & 4.00 & 0.43 & 161.60 & 355.00 & 41.06 & 3.99 & 0.64 & 231.05 & 390.76 & 77.65 & 3.99 & 0.87 \\
\hline 109.70 & 289.68 & 12.26 & 4.10 & 0.44 & 160.90 & 355.81 & 41.00 & 3.97 & 0.64 & 231.40 & 391.15 & 76.61 & 3.97 & 0.85 \\
\hline 108.42 & 291.68 & 10.19 & 4.02 & 0.44 & 162.06 & 356.40 & 41 & 3.99 & 0.64 & 3 & 391.90 & 78.17 & 4.00 & 0.86 \\
\hline 109.45 & 293.65 & 10.19 & 4.01 & 0.44 & 161.75 & 357.53 & 41.42 & 4.01 & 0.64 & 230.80 & 392.43 & 76.19 & 3.98 & 0.86 \\
\hline 110.97 & 295.43 & 10.91 & 4.08 & 0.45 & 163.57 & 358.52 & 42.90 & 4.06 & 0.65 & 232.75 & 392.97 & 76.25 & 4.00 & 0.86 \\
\hline 110.42 & 297.43 & 10.00 & 3.97 & 0.44 & 164.63 & 26 & 42.91 & 4.02 & 0.65 & 233.87 & 393.48 & 82.25 & 4.07 & 0.89 \\
\hline 111.98 & 299.39 & 10.48 & 4.05 & 0.45 & 163.20 & 360.22 & 41.99 & 4.01 & 0.65 & 235.34 & 394.04 & 79.86 & 4.01 & 0.87 \\
\hline 112.55 & 301.19 & 10.77 & 4.04 & 0.45 & $103 . / 0$ & 360.88 & 41.30 & 0.91 & 0.05 & 230.11 & 394.66 & 76.29 & 3.98 & 0.86 \\
\hline 113.01 & 302.91 & 10.56 & 4.07 & 0.46 & 165.70 & 361.86 & 42.03 & 4.01 & 0.65 & 234.43 & 395.14 & 78.51 & 4.00 & 0.87 \\
\hline 113.73 & 304.54 & 10.30 & 4.04 & 0.46 & 165.88 & 362.59 & 41.39 & 4.00 & 0.65 & 233.73 & 395.70 & 81.33 & 4.06 & 0.88 \\
\hline 114.18 & 306.50 & 10.00 & 4.00 & 0.46 & 166.37 & 363.32 & 42.32 & 4.06 & 0.65 & 232.70 & 396.21 & 79.67 & 4.00 & 0.88 \\
\hline 115.02 & 307.95 & 10.56 & 4.04 & 0.46 & 166.23 & 364.07 & 42.52 & 4.01 & 0.65 & 231.56 & 396.71 & 77.61 & 3.99 & 0.87 \\
\hline 115.72 & 309.85 & 10.62 & 4.05 & 0.47 & 167.97 & 364.89 & 42.02 & 4.02 & 0.66 & 236.63 & 397.26 & 78.66 & 4.04 & 0.88 \\
\hline 116.52 & 311.25 & 11.16 & 4.12 & 0.47 & 167.95 & 365.78 & 42.53 & 4.06 & 0.66 & 248.84 & 397.87 & 78.40 & 4.02 & 0.88 \\
\hline
\end{tabular}


Taking into account the indicators mentioned above (the average abundances 192 individuals for each macroinvertebrate family in Table 1, the eight families of macrophytes and the morphological indicators in Table 3 ) and assuming that all macroinvertebrate orders are present, $M=10, \log _{2}(192) \approx 7.58$, the expected value of $J P(G)$ is approximately 417. In the following we assume that $\omega\left(w_{\max }\right)=3$. It is well known that the expected value of the MIR index is 100 (see [15]). Thus, according to the results from Table 4 we can see that our index follows the trace of the information provided by the $J P(G)$ and MIR indexes. When the water quality is very low or low, $14.50 \leq I_{f}(G) \leq 97.25$; for a regular water quality $99.07 \leq I_{f}(G) \leq 148.86$ and if it is high or very high then $151.08 \leq I_{f}(G) \leq 248.84$. Moreover, we observe that biodiversity (as shown in the Shannon diversity index) remains in the same value range, regardless of the value achieved by the $I_{f}(G)$ index, which implies that the index $I_{f}(G)$ shows significant differences as compared to the Shannon diversity index. We can conclude that diversity is not a fundamental property to determine in the water quality.

In [25], it was proved that there is no correlation between the $J P(G)$ and $H^{\prime}$ indices. Below we calculate the Pearson's correlation coefficient to determine the level of correlation of the other indices with ours.

An important factor related to our index is that it can replicate the information provided by each of the indices it is based on. Now we calculate Pearson's correlation coefficient between the $I_{f}(G)$ index and the $J P(G), M I R$ and $H^{\prime}$ indices (see Figure 5). The $I_{f}(G)$ index has a strong direct correlation with the $J P(G)$ and MIR indices, resulting in a correlation of $R^{2}=0.8605$ and $R^{2}=0.7661$, respectively. However with Shannon diversity index the correlation was $R^{2}=0.0498$. Besides, it is essential that the index is unbiased, i.e., regardless of the values of the base indices, our index should not lean towards the behavior of any of them.
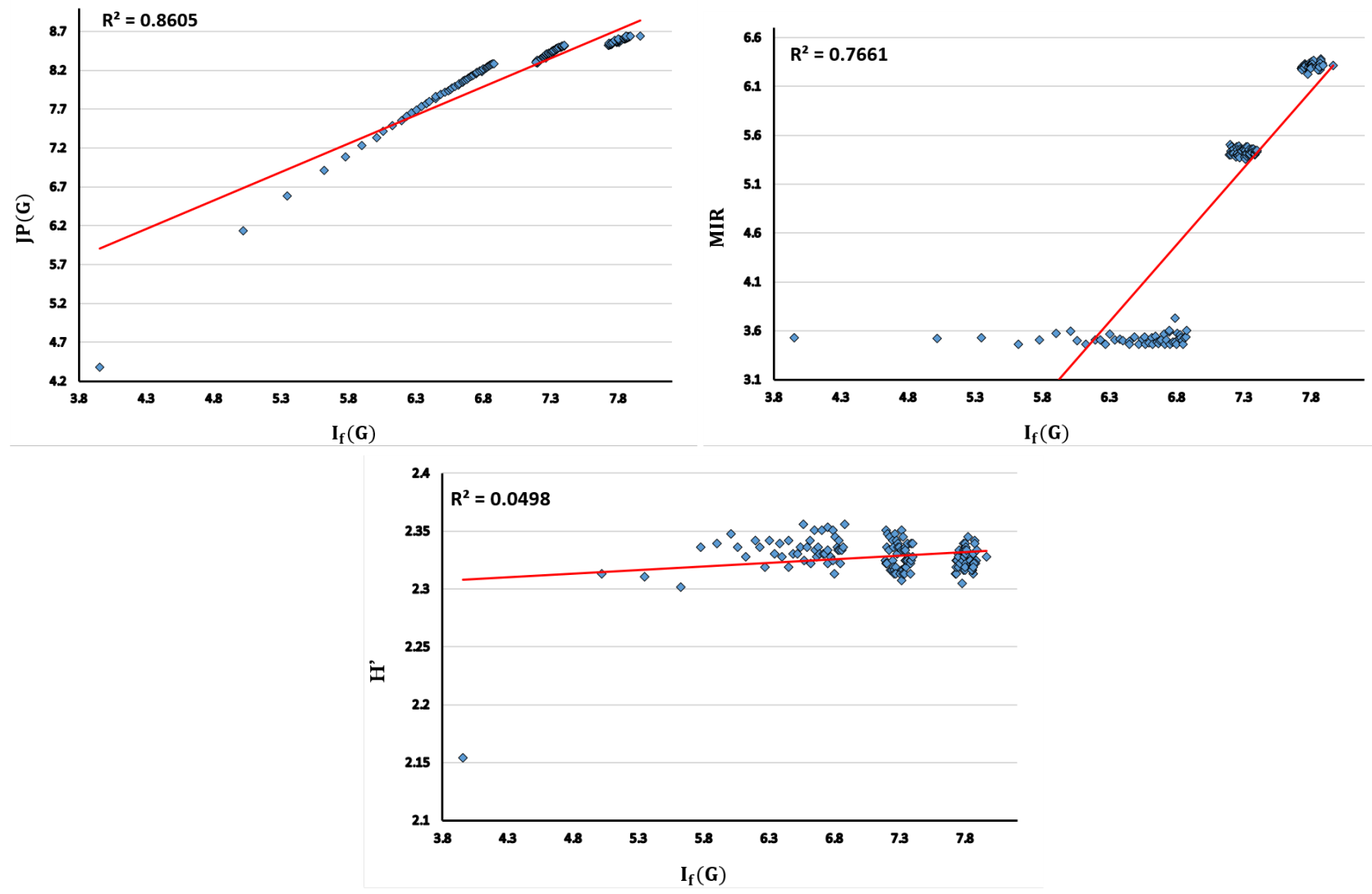

Figure 5. Scatter plots between the index $I_{f}(G)$ and the $J P(G)$, MIR and Shannon diversity indices for the 150 random networks constructed above. The index values are normalized with the function $\log _{2}(x+1)$. 
To prove the impartiality of the index $I_{f}(G)$, we have constructed 50 random samples where the index $J P(G)$ indicates a very low water quality in the first examples and very high water quality in the last examples. However, the MIR index indicates from high to low water quality and the morphological indicators obtained totally random values (see Figure 6). Note that, despite these differences, the values of the $I_{f}(G)$ index are in no way too close to any of the indices. This ensures that the index takes into account all the information from the biotic and abiotic indicators in a homogeneous way.

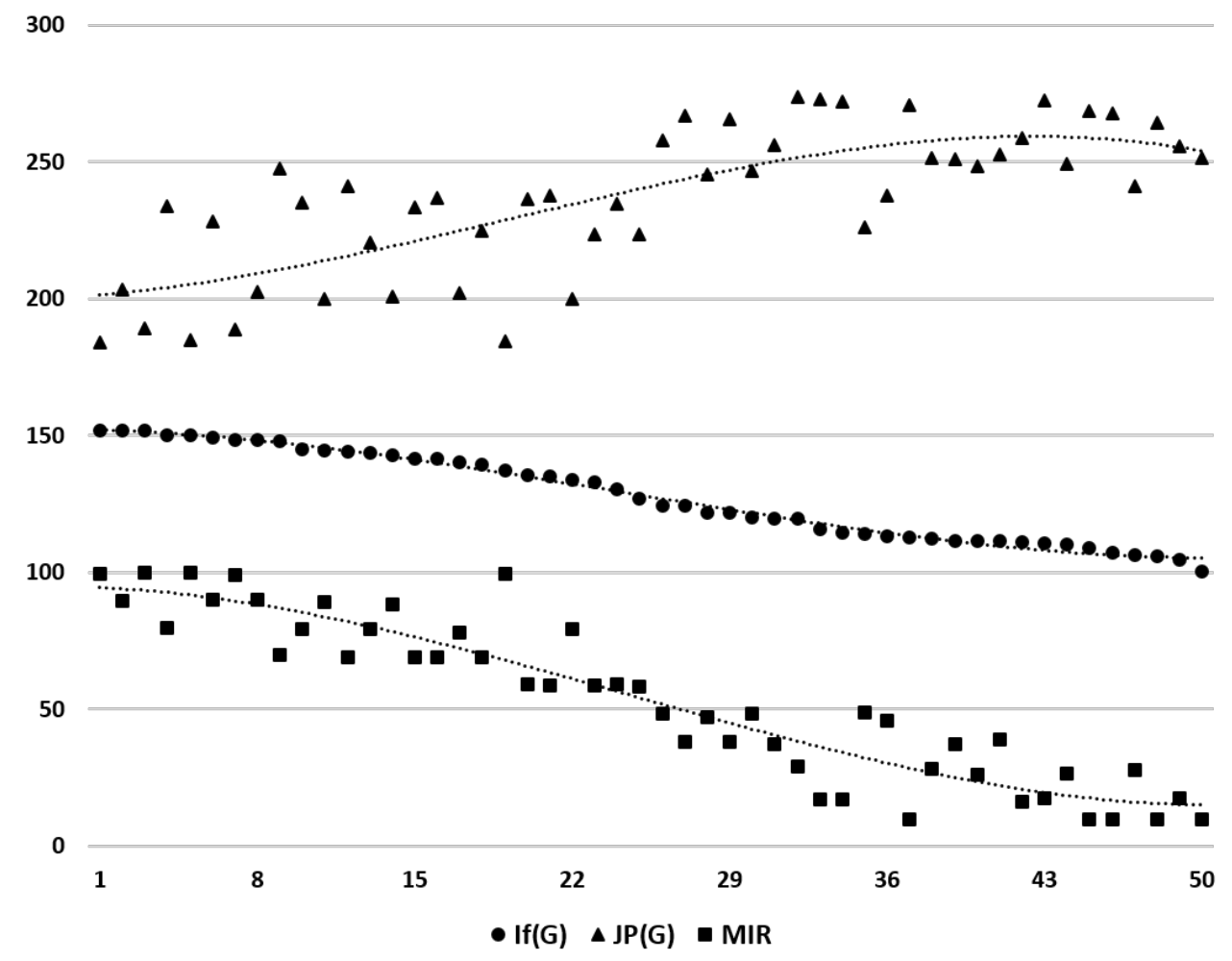

Figure 6. A graph where the values of the indices $I_{f}(G), J P(G)$ and $M I R$ are compared for 50 random instances. The abscissa axis indicates the 50 instances and the ordinate axis the value of each index for each instance.

\section{Structural Analysis of the Geometric Model}

So far we have analyzed our index with respect to the other indices used in the assessment of the water bodies quality taking only into account its possible value. To our geometric model, several statistical properties can be obtained, such as average degree, clustering or diameter can be defined from the adjacency matrix of the network, but none of them provides relevant information for the assessment of the water status. Here, we apply other technique to water quality assessment, which is based on the structural properties of the network $G$.

Besides information-theoretic mathematical measures, several other entropic network measures for estimating the disorder relations in complex networks have been explored in the context of network physics, see more in [33]. Moreover, correlation measures offer considerable insight into the structural properties displayed by complex networks. Generally, in some networks high degree vertices tend to attach to other high-degree vertices. At the same time, there are low degree vertices to attach to other low-degree vertices, thus involving anticorrelation. The latter cases are common in most biological nets, whereas the former case is common in social and collaboration networks, see [33]. Thus, applying Shannon's information measure, the network entropy measure is a more widely used one. 
This measure does not incorporate the weight of the edges in its analysis, so that in [34] it is defined the measure called Medium Articulation $(M A(G))$ that obtains its maximum for networks with a medium number of edges, whereas it vanishes for extremal networks (null and complete networks). Now, note that the network of the geometric model is bipartite, taking $V=V_{1} \cup V_{2}$, where $V_{1}=\mathcal{T} \cup \mathcal{M} \cup \mathcal{W}$ and $V_{2}=\mathcal{A} \cup \mathcal{P}$. Thus, the measure reaches the maximum when the bipartite network is complete, and it attains the minimum when there are no edges in the network (the total number of edges in the complete bipartite networks is about half of the total number of possible edges) defined by:

$$
M A(G)=R(G) * I(G)
$$

where,

$$
R(G)=-\sum_{u, v \in V} T_{u v} \log \left(\frac{T_{u v}^{2}}{\sum_{x \in N(v)} T_{x v} \sum_{y \in N(u)} T_{y u}}\right)
$$

and

$$
I(G)=\sum_{u, v \in V} T_{u v} \log \left(\frac{T_{u v}}{\sum_{x \in N(v)} T_{x v} \sum_{y \in N(u)} T_{y u}}\right) .
$$

Here $R(G)$ represents the redundancy and $I(G)$ the mutual information [34]. As a consequence,

$$
T_{u v}=\frac{\omega(u v)}{\sum_{x, y \in V} \omega(x y)} .
$$

Another widely known structural property of a network is the connectivity, denoted by $\alpha \in[0,1]$, and defined as the ratio of current adjacent pairs over the total number of possible adjacent pairs (see [35]). In particular, for our geometric model, $\alpha=\frac{|E|}{\left(n_{1}+n_{2}\right)\left(|T|+n_{3}\right)+|W| * n_{2}}=\frac{|E|}{\left(n_{1}+n_{2}\right)\left(10+n_{3}\right)+3 * n_{2}}$. Furthermore, we can see that the relationship between morphological and biotic indicators is always present, so that for our model we can establish the connectivity as $\alpha=\frac{|E(G[\mathcal{T} \cup \mathcal{A} \cup \mathcal{P} \cup \mathcal{W}])|}{10 *\left(n_{1}+n_{2}\right)+3 * n_{2}}$. The connectivity of a network is an important measure of its resilience as a network. Thus, it is a good indicator of the ecological state of ecosystems.

Now we compare the values $M A(G), \alpha$ and $\rho(G)$ in 100 constructed random samples. For that, we use the same parameters as in the previous section. From Figure 7, it is clear that there is no relationship between the $\rho(G)$ and $\alpha$ index. However, it is also clear that there is an strong inverse relationship between the indexes $I_{f}(G)$ and $M A(G)$. This implies that the index $\rho(G)$ shows significant differences as compared to the connectivity index, but for the Medium Articulation of the network holds the contrary. 

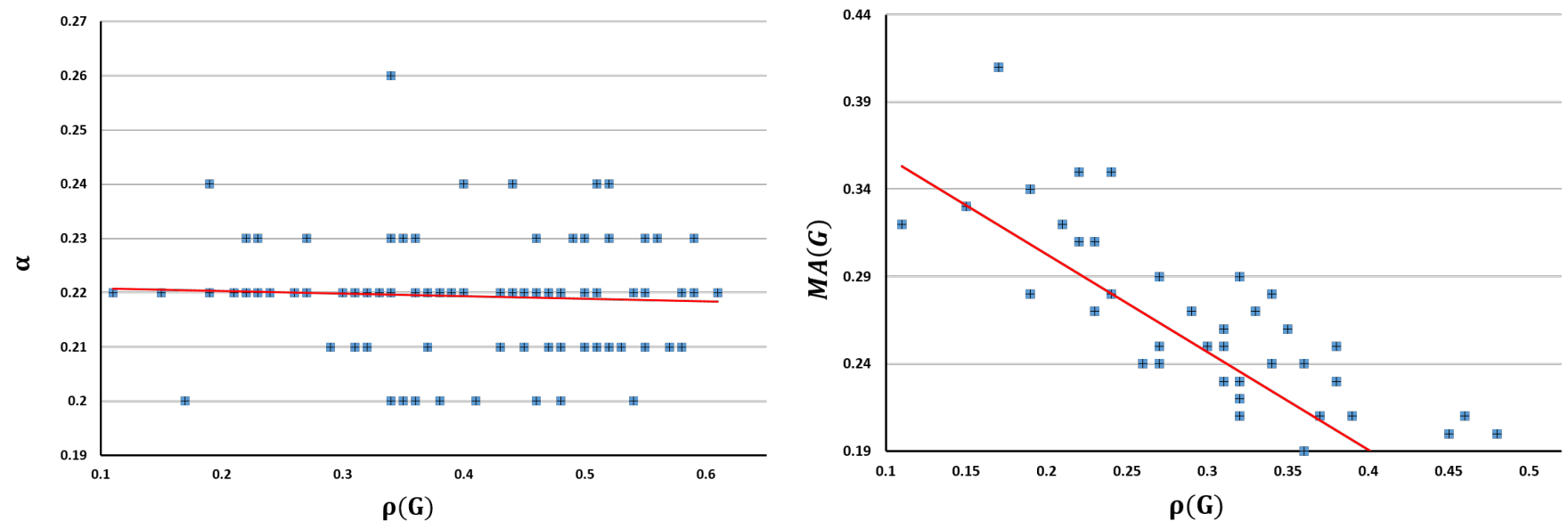

Figure 7. Scatter plots between $M A(G), \rho(G)$ and $\alpha$ indices for 100 random networks.

\section{Conclusions}

In this article, we propose a new multimetric index $I_{f}(G)$ to determine the water quality in lagoons. The geometric representation of a phenomenon associated with an ecological system allowed us to propose this index in which we have associated the elements of the ecosystem with the vertices of a network and the relationships between them were represented by the corresponding edges. The proposed index includes variables and relations which are not used in other indices reported in the literature (e.g., Multimetric Phytoplankton Index (MPI), Ecofuntional Quality Index (EQI), Weighted Biotic Index (WBI), Index of Biotic Integrity (IBI)); for example, dominant taxon, macroinvertebrate family richness, abundance and richness of macrophytes and the relation between biotic elements and morphological indicators.

We determined the five classes in which the status of a water body is classified, from very low to very high. We also compared the $I_{f}(G)$ index with several well-known indices used in the water quality study and have succeeded to verify the direct relationship between them, validating it with Pearson's correlation coefficient, obtaining a strong correlated with the $J P(G)$ and MIR indices $\left(R^{2}=0.8605\right.$ and $R^{2}=0.7661$, respectively). However, there is a weak correlation between our index and Shannon diversity index, as shown below $R^{2}=0.0498$.

We showed that the structure of the proposed network, through the Medium Articulation measure, has a tight relationship with the proposed index. This is extremely important since the missing relationships in the geometric model can be detected and criteria to improve or add these missing relationships can be established. In particular, the practitioners will be able to take specific actions based on the missing relationships in the network.

As to the future work, the proposed geometric representation can be expanded by adding other biotic indicators, as long as they fit the qualitative properties of the research. In summary, the interdisciplinary approach to water quality assessment by means of bioindicators and morphological inidicators allows us to reach a better approximation for the water quality evaluation in a lagoon.

Author Contributions: The authors contributed equally to this research. Investigation, F.A.H.-M., J.L.R.-A., M.R.-U., J.V.-G., J.M.S.-A. and N.V.; and writing-review and editing, F.A.H.-M., J.L.R.-A., M.R.-U., J.V.-G., J.M.S.-A. and N.V. All authors have read and agreed to the published version of the manuscript.

Funding: This work was supported by RDSC-UAGro publication grant. J.L.R.-A. was supported by RDSC-UAGro IDPTC-PRODEP/20493 grant. J.M.S.-A. was supported by a grant from Agencia Estatal de Investigación (PID2019-106433GBI00/AEI/10.13039/501100011033), Spain. N.V. was supported by CONACyT 2020-000019-01NACV-00008 and PRODEP grant for research stays. 
Institutional Review Board Statement: Not applicable.

Informed Consent Statement: Not applicable.

Data Availability Statement: Available datasets were analyzed in this study. This data can be found here: https://drive.google.com/drive/folders/1vWokUOUzDhCQ-qiPSVfL4LolBQ9oLvmS?usp= sharing (accessed on 19 August 2020).

Acknowledgments: The first author thanks UAGro Postgraduate in Environmental Sciences (PNPC:00672) for the CONACYT Scholarship (CVU: 745270) awarded for doctoral studies.

Conflicts of Interest: The authors declare no conflict of interest.

\section{References}

1. Muñoz-Piña, C.; Guevara, A.; Torres, J.M.; Braña, J. Paying for the Hydrological Services of Mexico's Forests: Analysis, Negotiations and Results. Ecol. Econ. 2008, 65, 725-736. [CrossRef]

2. Karr, J.R. Assessment of Biotic Integrity Using Fish Communities. Fisheries 1981, 6, 21-27. [CrossRef]

3. Karr, J.R. Defining and measuring river health. Freshw. Biol. 1999, 41, 221-234. [CrossRef]

4. Furse, M.T.; Hering, D.; Brabec, K.; Buffagni, A.; Sandin, L.; Verdonschot, P.F. The ecological status of European rivers: evaluation and intercalibration of assessment methods. Hydrobiologia 2006, 566, 1-2. [CrossRef]

5. Resh, V.H.; Norris, R.H.; Barbour, M.T. Design and implementation of rapid assessment approaches for wáter resource monitoring using benthic macroinvertebrates. Austral Ecol. 1995, 20, 108-121. [CrossRef]

6. Bonada, N.; Prat, N.; Resh, V.H.; Statzner, B. Developments in aquatic insect biomonitoring: A comparativeanalysis of approaches. Annu. Rev. Entomol. 2006, 51, 495-523. [CrossRef]

7. Aazami, J.; Moradpour, H.; Zamani, A.; Kianimehr, N. Ecological quality assessment of Kor River in Fars Province using macroinvertebrates indices. Int. J. Environ. Sci. Technol. 2019, 16, 6935-6944. [CrossRef]

8. Lücke, J.D.; Johnson, R.K. Detection of ecological change in stream macroinvertebrate assemblages using single metric, multimetric or multivariate approaches. Ecol. Indic. 2019, 9, 659-669. [CrossRef]

9. Saloom, M.E.; Scot Duncan, R. Low dissolved oxygen levels reduce anti-predation behaviours of the freshwater clam Corbicula fluminea. Freshw. Biol. 2005, 50, 1233-1238. [CrossRef]

10. Cross, W.F.; Wallace, J.B.; Rosemond, A.D.; Eggert, S.L. Whole-system nutrient enrichment increases secondary production in a detritus-based ecosystem. Ecology 2006, 87, 1556-1565. [CrossRef]

11. Steinman, A.D.; Rosen, B.H. Lotic-lentic linkages associated with Lake Okeechobee, Florida. J. N. Am. Benthol. Soc. 2000, 19, 733-741. [CrossRef]

12. Haury, J.; Peltre, M.C.; Trémolières, M.; Barbe, J.; Thiebaut, G.; Bernez, I.; Daniel, H.; Chatenet, P.; Haan-Archipof, G.; Muller, S.; et al. A new method to assess water trophy and organic pollution-the Macrophytes Biological Index for Rivers (IBMR): Its application to different types of river and pollution. Hydrobiologia 2006, 570, 153-158. [CrossRef]

13. O'Hare, M.; Baattrup-Pedersen, A.; Nijboer, R.C.; Szoszkiewicz, K.; Ferreira, T. Macrophyte communities of European streams with altered physical habitat. Hydrobiologia 2006, 566, 197-210. [CrossRef]

14. Demars, B.O.L.; Potts, J.M.; Tremolieres, M.; Thiebaut, G.; Gougelin, N.; Nordmann, V. River macrophyte indices: Not the Holy Grail! Freshw. Biol. 2012, 57, 1745-1759. [CrossRef]

15. Muratov, R.; Zhamangara, A.; Beisenova, R.; Akbayeva, L.; Szoszkiewicz, K.; Jusik, S.; Gebler, D. An attempt to prepare Macrophyte Index for Rivers for assessment watercourses in Kazakhstan. Meteorol. Hydrol. Water Manag. Res. Oper. Appl. 2015, 3, 27-32. [CrossRef]

16. Rinaldi, M.; Surian, N.; Comiti, F.; Bussettini, M.; Belletti, B.; Nardi, L.; Golfieri, B. Guidebook for the evaluation of stream morphological conditions by the Morphological Quality Index (MQI). Version 2012, 1, 85.

17. Wyżga, B.; Zawiejska, J.; Radecki-Pawlik, A.; Amirowicx, A. A method for the assessment of hydromorphological river quality and its application to the Czarny Page 49 of 177 Dunajec, Polish Carpathians. In Cultural Landscapes of River Valleys; Radecki-Pawlik, A., Hernik, J., Eds.; Agricultural University in Kraków: Kraków, Poland, 2010; pp. 145-164.

18. Wyżga, B.; Zawiejska, J.; Radecki-Pawlik, A.; Hajdukiewicz, H. Environmental change, hydromorphological reference conditions and the restoration of Polish Carpathian rivers. Earth Surf. Process. 2012. [CrossRef]

19. Rinaldi, M.; Surian, N.; Comiti, F.; Bussettini, M. A method for the assessment and analysis of the hydromorphological condition of Italian streams: the Morphological Quality Index (MQI). Geomorphology 2013, 180-181, 96-108. [CrossRef]

20. Pérez-Domínguez, R.; Maci, S.; Courrat, A.; Lepage, M.; Borja, A.; Uriarte, A.; Netoe, J.M.; Cabral, H.; Raykov, V.S.; Franco, A.; et al. Current developments on fish-based indices to assess ecological-quality status of estuaries and lagoons. Ecol. Indic. 2012, 23, 34-45. [CrossRef]

21. Hawkes, H.A. Origin and development of the biological monitoring working party score system. Water Res. 1998, 32, 964-968. [CrossRef]

22. Jun, Y.C.; Won, D.H.; Lee, S.H.; Kong, D.S.; Hwang, S.J. A multimetric benthic macroinvertebrate index for the assessment of stream biotic integrity in Korea. Int. J. Environ. Res. Public Health 2012, 9, 3599-3628. [CrossRef] [PubMed] 
23. Bazzoni, A.M.; Pulina, S.I.L.V.I.A.; Padedda, B.M.; Satta, C.T.; Lugliè, A.; Sechi, N.; Facca, C. Water quality evaluation in Mediterranean lagoons using the Multimetric Phytoplankton Index (MPI): study cases from Sardinia. Transitional Waters Bull. 2013, 7, 64-76.

24. Lucena-Moya, P.; Pardo, I. An invertebrate multimetric index to classify the ecological status of small coastal lagoons in the Mediterranean ecoregion (MIBIIN). Mar. Freshw. Res. 2012, 63, 801-814. [CrossRef]

25. Pineda-Pineda, J.J.; Martínez-Martínez, C.T.; Méndez-Bermúdez, J.A.; Muñoz-Rojas, J.; Sigarreta, J.M. Application of Bipartite Networks to the Study of Water Quality. Sustainability 2020, 12, 5143. [CrossRef]

26. Pineda Pineda, J.J.; Rosas Acevedo, J.L.; Hernández Gómez, J.C.; Rosario Cayetano, O.; Sigarreta Almira, J.M. Approximation to the Study of Water Quality. 2018. Available online: http://ri.uagro.mx/handle/uagro/822 (accessed on 19 August 2020 ).

27. Álvarez-Arango, L.F.; Pélaez-Sánchez, E. Condiciones ambientales y comunidades acuáticas de los ríos afluentes al sistema de embalses Punchiná-San Lorenzo-Calderas. In En: Cambios y Tendencias en la Limnología de un Sistema de Embalses Andino 10 Años de Estudio de los Ecosistemas del Complejo Punchiná-San Lorenzo-Calderas; Ríos-Pulgarín, M.I., Benjumea-Hoyos, C.A., Villabona-González, S.L., Eds.; ISAGEN-Fondo Editorial UCO, Medellín, Colombia: 2020 ; 312p.

28. Szoszkiewicz, K.; Zbierska, J.; Jusik, S.; Zgoła, T. Makrofitowa Metoda Oceny Rzek. Podrecznik Metodyczny Do Oceny i Klasyfikacji Stanu Ekologicznego Wód Płynacych w Oparciu o Rosliny Wodne; Boguski Wydawnictwo Naukowe: Poznan, Poland, $2010 ;$ p. 81. (In Polish)

29. Gebler, D.; Kayzer, D.; Szoszkiewicz, K.; Budka, A. Artificial neural network modelling of macrophyte indices based on physico-chemical characteristics of water. Hydrobiologia 2014, 737, 215-224. [CrossRef]

30. Shannon, C.E. The mathematical theory of communication. 1963. MD Comput. Comput. Med Pract. 1997, 14, 306-317.

31. Magnussen, S.; Boyle, T.J.B. Estimating sample size for inference about the Shannon-Weaver and the Simpson indices of species diversity. For. Ecol. Manag. 1995, 78, 71-84. [CrossRef]

32. Pla, L. Inferencia basada en el índice de Shannon y la riqueza. Interciencia 2006, 31, 583-590.

33. Solé, R.V.; Valverde, S. Information theory of complex networks: On evolution and architectural constraints. In Complex Networks; Springer: Berlin/Heidelberg, Germany, 2004; pp. 189-207.

34. Wilhelm, T.; Hollunder, J. Information theoretic description of networks. Phys. A Stat. Mech. Its Appl. 2007, 385, 385-396. [CrossRef]

35. Martínez-Martínez, C.T.; Méndez-Bermúdez, J.A.; Moreno, Y.; Pineda-Pineda, J.J.; Sigarreta, J.M. Spectral and localization properties of random bipartite graphs. Chaos Solitons Fractals X 2019, 3, 100021. [CrossRef] 